Max-Planck-Institut für demografische Forschung

Max Planck Institute for Demographic Research

Doberaner Strasse 114 - D-18057 Rostock - GERMANY

Tel +49 (0) 3812081 - 0; Fax +49 (0) 3812081 - 202;

http://www.demogr.mpg.de

MPIDR WORKING PAPER WP 2002-029

JULY 2002

\title{
Determinants of individual
}

AIDS risk perception:

knowledge, behavioural control, and social influence

Laura Bernardi (bernardi@demogr.mpg.de)

This working paper has been approved for release by: Hans-Peter Kohler (kohler@ demogr.mpg.de) Head of the Research Group on Social Dynamics and Fertility.

(C) Copyright is held by the authors.

Working papers of the Max Planck Institute for Demographic Research receive only limited review. Views or opinions expressed in working papers are attributable to the authors and do not necessarily reflect those of the Institute. 
Determinants of individual AIDS risk perception: knowledge, behavioural control, and social influence

\author{
Laura Bernardi \\ Max Planck Institute for Demographic Research \\ Doberaner Strasse 114 \\ 18057, Rostock - Germany \\ tel. 0049-381-2081171 \\ fax 0049-381-2081471 \\ email: bernardi@demogr.mpg.de
}




\begin{abstract}
In sub-Saharan Africa an almost universal awareness of AIDS lethality and of HIV sexual transmission mechanism coexists together with a reluctance in adopting consequent preventive measures as protected sexual intercourse. The sociopsychological literature on health-related behaviour emphasises the perception of being at risk of HIV/AIDS infection as being one of the necessary conditions for preventive behaviour to be adopted. Analysing data from the Kenya Diffusion and Ideational Change (KDIC) Project, this paper investigates the determinants of the reported degree of risk perception of getting infected by HIV/AIDS. In particular, adopting a social interaction approach, we argue that individual risk perception is shaped by social network influences. We use information about conversation related to AIDS and HIV infection risk occurring among individuals and their social network members. We are able to show to what extent neglecting individuals' reciprocal influences into explanatory models leads to a mis-estimation of the weight of other factors, as AIDS related knowledge and behavioural factors.
\end{abstract}

Additional index words: Kenya, social networks 


\subsection{Introduction}

Sub-Saharan Africa accounts for two-thirds of the world's HIV/AIDS pandemic, and a clear cut AIDS belt runs east and south from Central Africa. (Caldwell 1997). The growing AIDS epidemic in sub-Saharan Africa, is causing a rapid rise in the death rates of the sexually active share of the population (most adults dying of AIDS are under 40 years of age). The severe demographic and social consequences of the epidemic, such as an emerging unbalanced age structure, have already been vigorously described elsewhere (Ainsworth and Teokul 2000, Caldwell 1997).

Infection rate depends partially on macro-epidemiological and socio-economic determinants that are beyond individual control and partially on individual behaviour. Population mobility, incubation duration, sexual networks in the community, poverty, health infrastructures and gender relationships are examples of the first type of determinants. Individual sexual behaviour, the number of sexual partners, their selection, the use of protection during sexual intercourse are examples of the second type [Fontanet and Piot 1997]. In this paper we focus on this latter micro perspective, investigating what is behind the individual perception of being at a certain level of infection risk.

The adoption of preventive behaviour would be the only protection against the virus, if a major medical breakthrough stays a long way off ${ }^{1}$. Despite an almost universal awareness of AIDS lethality and of HIV sexual transmission, there is no correspondence with a widespread adoption of preventive measures, leads to think that there are additional factors that ought to be taken into account. The sociopsychological literature on health-related behaviour emphasises the perception of being at risk of infection as being one of the necessary conditions for behavioural change. Moreover, the degree of the perceived risk seems to affect individuals' actual control in adopting preventive measures. For instance, in the literature focusing on contexts with high AIDS prevalence, it is a common finding that the wife's ability to ask her husband to use a condom is significantly enhanced by the extent she feels to be at risk of HIV/AIDS (Wollf and Blanc 2000, Schroder et al. 2001).

\footnotetext{
${ }^{1}$ Or at least one that would be universally affordable and available.
} 
Sensitivity to risk depends also on other factors than knowledge of infection mechanisms and behaviour, as individual awareness of the illness (its prevalence, the severity of its symptoms, its lethality) and the perception of the general health status (Renne 1997). Individual risk assessment and shared common sense attitudes influence the perceived value attached to the consequences of actions and to the balance of gains and losses behavioural choices imply. If the magnitude of the potential loss is perceived as small enough, then the acceptability of undertaking the action is higher. On the one hand, these confounding factors are not easily measurable and they render make the relationship between individual knowledge and risk perception a fuzzy one. On the other hand, they stress the need to take into account personal networks such as the concrete context where knowledge is constructed and risk boundaries and acceptability is defined.

In this paper we consider models of social interaction as determinants of the individual reported level of risk perception. In light of our findings we question the results of studies which tend to limit the determinants of risk perception to microindividual and macro-context characteristics. Models of social interaction assume that individuals' beliefs and opinions are the product of a social construction activity performed within their social networks. According to this perspective, inter-individual relationships and the content of these relationships have some influence on individual perceptions and behaviours and on the associations between those perceptions and behaviours. We argue that individual risk perception is shaped by social network influences and that, therefore, ignoring individuals' reciprocal influences leads to over- or underestimating the weight of other factors [Erickson 1988]. The broader collective experience of significant others offers a large pool of cases to be observed, reported and evaluated, providing the context for the creation of shared knowledge and risk assessment. Beside the pioneering work by (Watkins \& Schatz 2001, Buehler and Kohler 2002), the role of social interaction processes on individual risk perception has not been thoroughly investigated in the literature, mostly because of the lack of specific data on individual social network members. The Kenya Diffusion and Ideational Change Project Survey KDICP (Watkins and collaborators; see http://www.pop.upenn.edu/networks) we use in our analysis contains information on individual ego-centered networks and on the reported opinion of network members about HIV/AIDS infection risk. 


\subsection{Determinants of risk perception}

Individuals' reported state of risk is generally included as an explanatory variable in behavioural models, but its very determinants are relatively under-investigated. We will consider three sets of potential influential factors which are not considered jointly in any of the previous studies we are aware of:

a) Knowledge of the mechanisms of HIV spread: risk perception is dependent on the capability to assess the relationship between behaviour and the modes of transmission of the virus. Individuals may have a correct or incorrect understanding of what the actual HIV infection agents are. When an individual is aware that one or the other documented modes of HIV transmission can lead to infection, we will refer to this awareness as correct knowledge (i.e. sexual intercourse, injection of infected blood, etc...). Conversely, we will refer to the individual's incorrect knowledge to indicate endorsement of false beliefs about transmission mechanisms (e.g., beliefs that HIV is transmitted by mosquito bites, kisses, touching an ill person and so forth). Correct information about infection mechanisms, including information about possible ways of protecting against it (condom use, reduced number of sexual partners, abstinence, sterilised injections) are often provided by health centres, or by specific programs aimed at enforcing the adoption of preventive behaviour. There is evidence that acquiring a certain level of correct information does not necessarily eliminate the possibility of holding other false beliefs or there being non-documented modes of transmission [Ingham 1995]. As some of the previous research has shown, there is a relation between knowledge of AIDS spread mechanisms and risk perception. However in a recent review study considering 80 studies centered on this topic Peruga and Celentano (1993) conclude that there is no clear direct association between the two. Correct and incorrect knowledge overlap, as new information is never neutrally accepted. Individuals read new information in the light of their previous conceptions, attitudes and ideas through which they interpret their environment and they explain events. This filtering of scientific knowledge through local beliefs is not specific to non-western contexts (LeBlanc 1993). For instance, a study about knowledge of HIV/AIDS among college students in Quebec reports:

"when the relation of the biomedical information and official safer-sex guidelines to personal actions was explored, it became apparent that although the young adults possessed scientific knowledge, it was common sense knowledge, or folk knowledge which guided their own perceptions 
and rules of action. This folk or common sense knowledge consisted of scientifically based knowledge filtered through their experiences and those of their peers" (Maticka-Tyndale 1992).

Sometimes over-detailed information given by health programs, specifying all the possible ways of transmission, including the less likely ones, can be confounding, since it may deflect attention from the main concept and reduce the degree to which the whole message is received. In contrast, it has been shown that focusing on the main danger relating to everyday behaviour, where this information is passed by mouth-to-mouth communication, may be more efficient (Schoepf 1991). A recent study analysing the co-occurrence of correct and incorrect knowledge about HIV/AIDS transmission mechanisms in El Salvador reaches the following conclusions: first, incorrect beliefs co-occur with accurate knowledge and are largely independent from it $^{2}$; second, the higher the level of accurate and inaccurate knowledge, the higher the level of risk perception and the intensity of the perceived risk; finally, more incorrect knowledge is correlated with higher uncertainty concerning the evaluation of one's risk status (London \& Aroyds 2000). The authors speculate about the possibility that the observed co-occurrence could be due to different transmission channels through which correct and incorrect information spreads. Information on documented modes of transmission pass through media, prevention campaigns and health services, while "more general beliefs about contagion and disease, not strictly related to HIV/AIDS" are exchanged in social occasions.

b) Behavioural control and actual behaviour: individual risk perception depends on the individual perceived control of her capability to take preventive measures against the infection and, of course, on actual behaviour. Risk self-assessment is the product of one's knowledge (whether correct or not) and of the "riskiness" of one's behaviour. Depending on one or the other of these two factors, perceived risk may or may not be accurate compared to actual risk. An affirmative answer to the question "do you feel at risk of getting AIDS?" might result from two different combinations of knowledge and behaviour. Either one holds incorrect beliefs about AIDS spread and behaves safely; or, alternatively, one engages in unsafe behaviours while

\footnotetext{
${ }^{2}$ The authors speculate about the possibility that such a co-occurrence could be due to different transmission channels through which correct and incorrect information spreads. Information on documented modes of
} 
possessing a correct understanding of its riskiness. The same reasoning holds for people who respond that they do not feel at risk. They might not know what they should actually fear, or they might simply behave in a safe way and be aware of it. A study in north-east Thailand reports that in that region women do not perceive that they are at risk because of their husbands' unprotected "promiscuity". According to the authors, the reason for what seems to be an inconsistent evaluation of the situation can be found in the normative framework regulating male extra-marital sexual activities in the region. Here, husbands are expected to be discrete about their extramarital affairs, whereas wives are expected not to investigate further:

"The two norms, discretion, silence and non-acknowledgement in the first instance, and trust in the second, formed the social psychological barriers against women recognising their own risk and taking effective action to protect themselves" (Matika-Tyndale et al.1994).

In order to understand respondents' perception of risk (as well as the predicting value of risk perception in the adoption of preventive behaviour), we need information on the preventive measures they themselves perceive to be effective (e.g. adhering to morally correct behaviour). In addition, risk perception is affected by the degree of control people feel they have on their own and their partner's behaviour. If preventive measures are not viable, their knowledge does not help, reducing the sensation of being at risk. We will discuss this point in further detail later on.

c) Social networks: individual risk perception is dependent on the perception held by other members of her personal network. Individual risk perception, as well as individual knowledge, is likely to be subject to social environment influences, as long as social interaction allows information exchange, facilitates common evaluation and definition of the information meaning and of its validity. Sources of learning and influence may be considered more or less reliable depending on tie - i.e. its strength and network characteristics - i.e. its density. For instance, conversations about family planning indicated in semi-structured interviews by respondents took place mostly with people belonging to the same ethnic group, "as if it was not meaningful to talk about this topic with those of another ethnicity" (Watkins 2000). Paths and characteristics of informal contacts are dependent on local social reality. False beliefs 
about HIV infection, as well as considerations of what is considered an acceptable risk, may originate and diffuse in informal networks as rapidly as correct beliefs enhanced by programs. Likewise, it is plausible to assume that informal exchanges transform the content of messages coming from official information campaign programs promoting preventive behaviour ${ }^{3}$.

\subsection{Data source and analysis procedure}

Our data come from Luos, a polygynous population living on the shores of Lake Victoria in South Nyanza province, in Western Kenya ${ }^{4}$. The population presents little economic and social stratification. The main economic activities are subsistence agriculture, sale of cash crops, some wage labour and small-scale business. Differences in education level do not reflect major differences among residents' socio-economic status: those who complete secondary education try to leave the area to go and work in cities, but those who stay make a very similar living to those who have not. Housing mainly consists of independent mud huts, covered with thatch or metal roofs. Social behaviour marks gender differences, sharply defining the boundaries for social interaction in public, as we were able to observe directly in the field and as was confirmed by survey data: men generally talk and work with men, women with women. Even on the occasion of gender-mixed ceremonies, such as marriages and funerals, it is common to see all the women sitting on one side and all the men on the other. There is a sense of inappropriateness, a social norm, attached to seeing an unrelated woman and man talking to each other.

The estimated AIDS prevalence in the region, based on data from local antinatal clinics, was $27.5 \%$ in 1995 and in 1998, two years before the survey (UNAIDS 2000). Estimations of age-specific mortality rates confirm the presence of a rapid growth of the epidemic in the area: mortality has doubled in 10 years ${ }^{5}$, and excess of deaths appears to be clustering around the age group 30-49 (Weinreb 1999) ${ }^{6}$.

\footnotetext{
${ }^{3}$ Drawing on her extensive knowledge of the field and on her qualitative data, Watkins advances the hypothesis that information given by health personnel might change once they discard their official role (personal conversation during fieldwork in S. Nyanza).

${ }^{4}$ Further information on the sampling of the longitudinal study as well as a description of the research area can be found on http://www.pop.upenn.edu/networks/field/sampling/sample_kenya.htm.

${ }^{5}$ Mortality rates are based on the inter survey period observed deaths and correspondent estimations of agespecific rates for the complete survey sample aged between 20-59, a rate for 10-year age groups (Weinreb 1999).

${ }^{6}$ Estimations are based on deaths occurred during the 2-year time elapsed from the first and the second wave of the survey, 1994-95 and 1996-97.
} 
Awareness of AIDS prevalence and of its lethality is also widespread. According to the 1993 Kenya DHS, in Nyanza region, 99\% of the respondents' had heard about the presence of AIDS. The median number of people among relatives, friends and neighbours who were reported as having died of AIDS is 4 for women and 5 for men. AIDS visibility and the generalised frequent experience of death that is associated with it, reveals a widespread awareness of the presence of the epidemic. Extra-marital sexual activity is also acknowledged and, to some extent, accepted for men and women alike. One out of two respondents, and $58 \%$ of the women, disagree on the statement that "man can be satisfied with just one sexual partner" (the figure decreases only to $35 \%$ and $42 \%$ for women). Only $30 \%$ of women, and $40 \%$ of men, would state that it was unlikely that their spouse had been unfaithful to them.

There is both quantitative and qualitative evidence that people in the region engage in casual conversations about AIDS, the acceptability of condoms and the criteria for choosing safe sexual partners (Watkins and Schatz 2001). They compare and comment on models and practices of sexual behaviour with those of "appropriate behaviour" promoted in South Nyanza by international agencies and the government of Kenya ${ }^{7}$. Respondents reported that 9/10 of conversations about AIDS were taking place with people of the same sex.

Empirical analyses are based on the second wave of the Kenya Diffusion and Ideational Change (KDIC) Project. We use a subset of 424 couples extracted from the second wave of the survey, carried out in 1996-1997. This sub-sample allows matching of husbands' and wives' information. Polygynous unions are represented by couples formed by a man and one of his wives, who is randomly chosen (30\% of the sample lives in a polygamous marriage). The random selection of a wife (as suggested by Speizer and Yates 1998) is a necessary compromise to deal with two limitations: 1) there are few wives of order higher than one and information on the wife order is often missing, or, when present, its accuracy is difficult to ascertain; 2) during the fieldwork, we realised that wife order could be indifferently maintained after the woman's death, or updated in order to refer to the rank of surviving wives only.

\footnotetext{
${ }^{7}$ The uncertainty over the preventive measures to adopt and their acceptability is reflected also in official positions, as is evident in a very recent comment made by the current president of Kenya, Moi, after his government recently decided to import massive stocks of condoms. Adding to the voices of local religious leaders, by whom the decision had been harshly criticised as promoting promiscuity, he stated: "as a president, I am shy that I am spending millions of shillings importing those things". His advice was to "refrain from sex for at least 2 years" (Reuters, 12 July 2001).
} 
On the assumption that an individual's characteristics and social environment have an effect on individual degree of risk perception, we estimate three different ordered logistic regression models (Greene 2000), for men and women separately. The rationale for considering men's and women's analysis separately is the genderdivided nature of the communication networks in Luo society. Besides sociodemographic control variables, in the first model we include independent variables accounting for individual knowledge of the mechanisms of AIDS spread. Next, we introduce variables referring to individual perceived control on preventing infection. Finally, in the last model, we consider social network characteristics and justify why this latter model should be the preferred one.

\section{Dependent variable}

Degree of risk perception: Two survey questions are useful in order to measure the risk perception of getting infected by HIV. First, a filter-question to assess whether the respondent feels at risk or not. Second, a question asking to specify the level of risk perceived to be answered only by those who felt at risk, or who were uncertain about it $^{8}$. Summary statistics relative to these two variables in figure 1 indicate both that the fraction of the population feeling at moderate or great risk is an important one, and that there is a substantial dispersion in the level of perceived risk ${ }^{9}$.

\section{[FIG 1 ABOUT HERE]}

\section{Independent variables}

1) Knowledge about HIV/AIDS transmission modes. The correct and incorrect knowledge indexes in table 3.1 are based on a set of questions asked to test individual awareness of the disease, of its asymptotic transmission (i.e., not having visible symptoms) and of different modes of transmission, whether documented or not. The latter are illustrated in figure 2. We constructed a scale of correct knowledge, summing the total number of correct transmission modes the respondent cited. The

\footnotetext{
${ }^{8}$ A "don't know" answer to this question was not allowed. We therefore estimate only the probability of respondents shifting from a lower degree of risk perception to a higher one, with no room to distinguish between degrees of certainty.

${ }^{9}$ These latter percentages are always calculated with reference to the total sample of 424 couples, because we included those who answered not being at risk in the first question, in the group of those whose perceived degree of risk is equal to "none".
} 
list of items is the same used in the 1993 Kenya DHS, and the amount of correct and incorrect knowledge about AIDS registered for Nyanza province is very close to that which we observed in the KDICP (second wave). The sum number is the indicator of individual knowledge ${ }^{10}$.

\section{[FIG 2 ABOUT HERE]}

In the case of incorrect knowledge we obtained the proportion of "yeses" out of the six undocumented modes listed in the questionnaire, but for homogeneity of comparison, we adopted the same procedure as for the correct knowledge indicator ${ }^{11}$. Mean score of correct knowledge is 2.2 for women and 2.3 for men, meaning at least 2-3 items were quoted on average by both men and women; $13 \%$ of the women and $20 \%$ of the men quote 4 or more documented modes of transmission. The same measure for incorrect knowledge gives, on average, 1.4 items, quoted by women and men alike; but only $33 \%$ of the women and $30 \%$ of the men have completely correct beliefs and score 0 undocumented items, while about $20 \%$ in both groups believe in 3 or more undocumented transmission modes. Correlation between correct and incorrect knowledge is very low, but significant: 0.07 for women and -0.07 for men (as for the study in El Salvador).

We used a negative binomial regression model (Greene 2000) to analyse the relation between the score on those scales and the general individual characteristics described above (results not shown). We could not derive any clear conclusion on the reciprocal influence of correct knowledge on incorrect knowledge. We would need further data on the specific information sources and on the dynamic of information flows in the four different sublocations where the study was done. In general, the lack of correlation between correct and incorrect knowledge at a global level should be tested against local variations. In fact, there could be population subgroups identified

\footnotetext{
${ }^{10}$ We could not calculate proportions because items were not listed, and therefore there was no common denominator.

${ }^{11}$ In fact, the interview procedure to assess knowledge of documented and undocumented modes was not homogeneous. In the first case, people were asked how AIDS virus is transmitted. They were not read a list in order to be sure that the answer would indicate individual actual knowledge and not mere compliance to the interviewer's suggestion On the contrary, in the case of undocumented modes of transmission, a list of 6 items was read beforehand. In this case respondents could limit themselves to answer yes/no/dk. Since the procedure followed in asking questions is different (reading a list of items or not), the two scales cannot be directly compared or summed up in a comprehensive index of total knowledge. Cronbach's alpha, assessing the reliability of a summative rating scale, can be calculated only for the incorrect knowledge scale, and in this case it is 0.71 (the value indicates a modest reliability of the scale in this case).
} 
by unobserved characteristics, for which the relationship is meaningful but assumes an opposite value, resulting in an apparent lack of correlation at the sublocation level $^{12}$.

2) Behavioural control. The second group of variables concerns the individual's perception of her capability to take preventive measures to protect herself against AIDS infection. Unfortunately we cannot use indicators of preventive measures adopted in the past in order to account for that amount of risk perception which would be due to having engaged or not in risk-taking behaviour. ${ }^{13}$ The first variable is a dummy, indicating whether respondent has ever done anything to protect against AIDS. The question was deliberately kept vague, in order to relate answers to a wide range of actions practised and understood in the community as preventive measures. These include abstinence, fidelity to spouse, condom use, eating certain types of herbs, selecting "healthy-looking" partners (Watkins and Schatz 2001). We expect that those having undertaken one of those actions, irrespective of its efficacy, would feel safer than those who have not.

The second variable indicates whether respondent would feel comfortable in suggesting to her spouse to use a condom. Condoms are not very popular among married couples in sub-Saharan Africa, either as contraceptive means, [Bond and Dover 1997; Nangendo 1998; Nzyuko et al. 1991], or because they are most often associated with AIDS prevention. This identification, in fact, makes it difficult for any of the two spouses to propose using condoms without implying an accusation or an admission of unfaithfulness [Bauni and Jarabi Obonyo 2000]. In our sample, for instance, $69.8 \%$ of women and $98.3 \%$ of men do not disagree with the sentence "condoms cannot be used with a serious girlfriend, because they cause mistrust or suspicion" 14 . Of the $25.5 \%$ of women declaring that they feel comfortable in suggesting condoms to their husbands, $71 \%$ agree that condoms are a sign of distrust in marriage. Likewise, $100 \%$ of men declare the same. However, feeling comfortable

\footnotetext{
${ }^{12}$ These results, however, might be misleading since we rejected, using a L-R test, that the coefficients are the same across sublocations (the likelihood ratio test does not reject the hypothesis of equal coefficients in the correct knowledge and risk perception regressions. It leads to rejection in the incorrect knowledge regression. Thus we analysed the relationship between correct knowledge and incorrect knowledge in the 4 sublocations separately, since they seem to shape how education and spouse's beliefs influence individual incorrect knowledge.

${ }^{13}$ The low response rate on this particular question makes it impossible to use it in the analysis. The question asked literally: "when was the last time you used condoms to prevent AIDS or other sexually transmitted diseases?"

${ }^{14}$ Of those, about $52 \%$ in both groups completely agree, the others do not agree nor disagree.
} 
about proposing the use of condoms could reduce the level of perceived risk, as it increases the safety of the sexual relationship with the spouse.

The third variable concerns husband's regular presence in the compound ${ }^{15}$. It is a common finding that extra-marital sex is higher when men's mobility is high (Orubuloye et al. 1993). In fact, seasonal labour migration to larger towns is common for men living in the area under study. These prolonged separations, while decreasing frequency of sexual intercourse among spouses ${ }^{16}$, increase the probability that both spouses engage in extra-marital sexual intercourse. In a study based on a focus group in the Kenya district of Nakuru, married women indicated reducing or stopping long trips as one of the most effective ways to protect themselves (Bauni and Jarabi Obonyo 2000). Consequently, we would expect risk to be perceived as lower when the husband is in the compound most of the time ${ }^{17}$.

\section{3) Social networks}

The last group of variables measure the size of respondents' personal networks and the risk perception of becoming infected by AIDS/HIV held by network members ${ }^{18}$. Conversational ego-centered networks were defined by asking individuals to name up to four persons with whom they had talked to about the possibility of being infected by AIDS/HIV (censored network size). A second question provides information on whether alters feel at risk of catching AIDS themselves (possible answers could be "yes", "no", "he/she does not know"). Using this information, we included in the model two variables, over and above network size: the first identifies respondents whose network includes at least one member feeling at risk, and the second the number of alters in the network feeling at risk. This latter variable measures the distinct effect on risk perception of the marginal network member

\footnotetext{
${ }^{15}$ Couple level of agreement on husband's presence in the compound is just fair (kappa statistics are 0.32), therefore we decided to use husband's answers for men and wife's answers for women; this choice is due to the fact that we are dealing with perceptions, therefore subjective opinion is what matters. Furthermore, the wording of the question is ambiguous enough to leave space for inconsistent answers within the couple ("does your husband / do you usually stay in the compound").

${ }^{16}$ Watkins and Schatz (2001) suggest that spouses' separation could also be interpreted as a voluntary strategy pushed by wives to reduce exposure to risk.

${ }_{17}$ We did not include direct measures of extramarital sexual activity, because we doubt this information to be reliable, as it is generally under-reported (UNAIDS 1999, Schopper 1993). In Kenya in particular, the fact that the government recommends fidelity as the main protection might be an additional reason to keep the information private.

${ }^{18}$ Unfortunately we do not have information on the reason for network partners hold ' ' such a belief (the question "why does [network partner name] thinks to be at no/little/moderate/great risk?" was introduced only at the time of the third wave).
} 
feeling at risk ${ }^{19}$. As we already argued, we believe risk perception to be a shared feeling in the restricted social context of personal networks, and AIDS risk a topic people evaluate together, comparing each other's opinions. Therefore, we expect the number of network partners feeling at risk to raise the probability of respondents feeling at higher risk. As a counter-check, we estimated an alternative model where network characteristics are the mirror image of the previous one. These are measured by a dummy variable that indicates respondents whose network includes at least one network partner that does not feel at risk, and by the number of people in the network who do not feel at risk.

\section{4) Control variables}

We control for selected socio-demographic individual characteristics and selected household characteristics.

Individual characteristics are: (a) age: age varies more for men, since the original sample consisted of women in their reproductive age (15-49) and their husbands, irrespective of men's age. (b) education: measured by the achieved level of education ${ }^{20}$. The susceptibility of being exposed to additional sources of information about AIDS/HIV might increase as a consequence of acquired reading skills and duration of exposure to school programs addressing the AIDS topic (for younger women). If institutional sources are given credibility, risk perception might increase together with educational attainment. At the same time, the opposite effect could be due to the increased sense of self-confidence and self-efficacy acquired by a person with higher education.

Household characteristics include: (a) A wealth index represented by a continuous variable, built counting the number of items (goods) possessed by the household. Each item is weighted by the inverse of its prevalence ${ }^{21}$ (items which are very common, such as a bed, possessed by $90 \%$ of the population, do not receive as

\footnotetext{
${ }^{19}$ We are not able to use other information on network structure, such as its density, because the number of observations would be insufficient.

${ }^{20}$ Achieved level of education might not be the ideal measure for exposure time to information about AIDS related topics, since drop outs are frequent, particularly among girls. Parents, investment in daughters' education is less common. Information on the number of years spent at school could not be used because there were too many missing data.

${ }^{21}$ Prevalence of items varies considerably. We follow the common assumption that owning something rare is an index of higher status than owning a more common good. We did not follow a similar weighing procedure in the construction of knowledge indexes because it is unlikely that the amount of individual knowledge does not contribute to risk perception in a different way according to its relative prevalence.
} 
much importance as a bicycle, owned only by one household out of three). (b) The place of residence, indicated by sublocation dummy variables. A sublocation is the smallest administrative unit in Kenya: there are differences between the sublocations in our sample, such as the presence of good road connections, market activities and health-related programs. Those characteristics could indicate the level of exposure to different external information sources as well as creating different patterns of receptiveness and interpretation of information about HIV/AIDS spread and its consequences. (c) Having lived out of South Nyanza for a period longer than 6 months, indicates whether the respondent has been subject to different context influences. (d) The type of household (monogamous or polygamous) account for the possibility that people living in a polygamous household might feel more at risk than those in a monogamous union (people in the area seems to fear particularly the higher sexual mobility of young wives).

\section{Results and discussion}

Tables 2 and 3 show the results of the logistic ordered regression models, for men and women respectively. Our preferred model is the one occupying the third column in each table (MMR3 and MFR3), where the introduction of network variables changes some of the coefficient estimations. Keeping in mind their limitations, we will discuss the outcome of the less restricted models first.

a) Baseline model. Models MMR1 and MFR1 examine the influence of the socio-economic characteristics, and including the level of correct and incorrect knowledge on the degree of risk perception of getting infected by AIDS. Age, primary school education, being in a polygamous union and having used family planning are all positively related to feeling at higher risk of infection. Age, secondary education, and having lived out of South Nyanza ${ }^{22}$ appear to be significant only for women, while the type of union is significant only for men. Age effect for women seems to be consistent with a longer exposure to risk to husband infidelity of older women, even if this effect is decreasing at higher ages. The significant negative coefficient of the variable indicating the woman's residence out of the region is difficult to interpret, since it is mediated by its influence on AIDS knowledge. In the analysis of the determinants of incorrect knowledge, we found that the same effect is registered on

\footnotetext{
${ }^{22}$ It is more difficult to ascertain why the same is not true for men.
} 
the false beliefs. Women having lived somewhere else are less subject to hold incorrect information on AIDS spread modes. This finding would support the hypothesis that beliefs are shared at the local level and socially constructed. For men, the absence of a significant age effect, and the negative sign of its coefficient, could simply be accounting for the varying effect of age on men's sexual behaviour, since the sample is on average older than their wives' one. Older men would feel less at risk due to diminished frequency of sexual intercourse. Differential education content by gender, promoting awareness of AIDS epidemics particularly among girls, can partially explain the difference in educational attainment. A more likely explanation is the exchange of sex-for-cash to pay school fees, one of the many expedients used by a girl to be able to continue being enrolled in education. The existence of relationships between "sugar daddies" (as older men dating school girls are usually called) and school girls is widely known, to the point that the local press often stresses the danger of those "exchanges". As expected, being aware of a wider range of modes of HIV transmission increases the feeling of being at higher risk, for men and women alike. On the contrary, no significant effect on risk perception corresponds to a larger number of false beliefs held by respondents, both men and women alike. For men, holding more incorrect beliefs decreases the perceived level of risk.

b) Behavioural control model. In models MMR2 and MFR2, the introduction of the three behavioural variables changes little the overall effect of individual sociodemographic characteristics, while all those three covariates capture significant differences in the degree of risk perception. Having done something to protect against infection is negatively and significantly related to the perception of being at higher risk for both men and women. By "protecting themselves" most women did not mean having used condoms, but having had sexual intercourse only with their husbands, which, obviously, does not protect from his potential infidelity. This can be evidence that, beyond the bio-medical explanatory framework, other causal chains link infection and sexual behaviour in our respondents' interpretation. For instance, in the specific case, holding a correct behaviour might be seen as providing a safety feeling (Obbo 1991, Ingstad 1990) ${ }^{23}$.

\footnotetext{
${ }^{23}$ This possibility began to seem plausible during the third wave of the study (January 2000), where some additional questions were added concerning the reasons why people who answered felt or did not feel at risk. They were also asked to specify how they feared getting infected. In matching the two items of information we were often faced with apparent inconsistencies: many women answered that they feared their husband as the cause of
} 
The second behavioural variable, indicating the possibility for prevention actually available to individuals, is the feeling of being comfortable in suggesting condom use to spouse. The effect is the same for both spouses. It departs from what we had expected, since those who feel comfortable in suggesting condom use to spouse are also those who perceive that they are at higher risk. In such a context it is reasonable to assume that, despite the offended reaction of the spouse, those who feel more at risk feel justified in asking for condom use, breaking the taboo against its use in the marital relation ${ }^{24}$.

Husband's presence in the compound has a reassuring effect as far as AIDS risk is concerned, both for men and women. While for the former the effect is not significant, women's perception of being at risk decreases in the direction we expected. On the contrary, when the husband is often absent, the wife thinks she has more reasons not to feel safe.

Summing up the results due to the introduction of the behavioural variables, women's degree of risk perception seems to be affected by the lack of potential control on some aspects of the marital sexual behaviour. The corresponding variables for men, on the other hand, are consistently insignificant. This would suggest that risk perception among men is less related to their wife's behaviour. This result is consistent with the belief that greater risk in marital infection comes from men because they are more likely to have extra-marital sexual relationships. However, an alternative explanation could be given for the same results. Women in South Nyanza are generally less able to decide when and if to have a protected sexual intercourse (Mason 1994). Thus women could more easily blame it on their husband's behaviour instead of their own. Risk perception is a compromise between what people know and what they want to know. In this perspective women might be more able to accept the idea of being at risk, since they do not have the power to impose the necessary behavioural change alone. Men's cost of admitting that the current conduct is unsafe is higher since they have more control over it. This dissonance could produce a denial of the risk itself rather than a behavioural change. Denial processes in the context of HIV/AIDS-related studies are recognised to be potential mechanisms in lowering perceived risk and recognition of responsibility for behaviour (Ben-Zur et al. 2000, 
Campbell 2000) $)^{25}$. Denial of risk might also emerge because individuals are heterogeneous in their attitude toward risk. Such a dispositional trait distinguishes between risk-averse and risk-seeking individuals: the former are motivated by desire for security and safety while the latter are motivated by desire for potential and opportunities. Therefore, in decision-making processes, risk-averse individuals would weight losses more than gains, while the opposite would be true for risk-taking individuals.

According to the socio-psychological literature, several factors influence risk aversion, i.e. the weight attributed to risks of undertaking or not certain actions. One of these is that inter-temporal discount effects might follow an inconstant rate [Laibson 1998, Kremer 1996] so that individuals adopt a temporal myopic behaviour, giving a higher discounting to shorter time delays than to longer. The consequence is choosing actions with immediate positive outcomes, despite anticipated negative consequences; in our case the long term consequences of engaging in unsafe sex today would not be relevant in determining behaviour in the short term.

A second possibility is that the telescopic effect of risk perception could be related to other variables than time. Adopting the "visceral factors" framework, physical proximity, sensory contacts and vividness of the sensation would "have a disproportionate effect on behaviour and tend to 'crowd out' virtually all goals other than that of mitigating the visceral factors [hunger, thirst, sexual desire]" (Loewentstein 1996).

Similarly, a third possibility is that the role of the anticipated severity of the consequences and of the capability of behavioural control could be reduced by other factors, whose action is limited in time, such as alcohol effects.

The possible presence of "infusing" factors (Etzioni 1992) which would affect rationally-based considerations of one's own risk, seem plausible when studying perception of AIDS risk. In fact, on the one hand there are studies which have recorded an indifferent or fatalistic attitude towards death (Kremer 1996, Orubuloye et al. 1993). This would reduce the estimation of the losses in engaging in unsafe

\footnotetext{
${ }^{24}$ The wording of the question "would you feel comfortable" had to be translated into the Luo language, and the meaning can assume several nuances (comment by local field supervisor during the revision of the questionnaire). ${ }^{25}$ A study among Israeli adolescents reports: "it seems that young people deny less the threat of HIV/AIDS, while denying more the relevance to themselves, and the notions that the responsibility for protection in sexual behaviours is theirs" (Ben-Zur 2000).
} 
sexual behaviour ${ }^{26}$. On the other hand, alcohol consumption often accompanies extramarital sexual intercourse, as a recent study among young Thai men shows (Van Landingham et al. 1997), reducing the weight of risk awareness. An example will make this point clearer: it has been recently observed that in industrialised countries there is a reversal in the trend of risky behaviours related to homosexual transmission (sharing of injections and unprotected sex). These behaviours are increasing, probably following the reduction of mortality observed after the introduction of the antiretroviral therapies. Once potential losses are reduced, preventive behaviour decreases accordingly. In contexts where treatment is not available and AIDS prevalence is higher, preventive behaviour is often disregarded for the opposite reason. Rather than a reduction in the potential losses, what matters is a reduction in the potential gains of using condoms. It was not rare to hear this sort of reasoning: where so many people are already dying or are most likely to be infected, I might well be infected already since I have been behaving in a risky way as much as they have. So why should I change behaviour now ${ }^{27}$ At least in experimental situations, this kind of argumentation is nothing new: individuals are known to be inclined to adopt a riskseeking behaviour when they are certain about losses (Kahneman and Tversky $1979)^{28}$. In other words, if there is virtually no chance that a safer option would lead to the expected outcome (avoid infection) because of the limited room left for further moves (high level of risk), the riskier option is likely to be a better choice (Lopes 1987). A sign of this underlying doubt of being already infected could be the negative attitude towards taking an HIV test. During the fieldwork in South Nyanza, we often asked informally why people would not go and be tested in order to be sure of their status. The answer was generally along these lines: "if I go to the hospital I die earlier” or "if I am ill I don't want to know, because if I know, I will die earlier". Several reasons might motivate this answer, considering the fact that, in almost all cases, people going to the hospital for a test are already in an advanced state of the

\footnotetext{
${ }^{26}$ As one participant in the 1996 BCC Lessons Learned Project in Kenya put it: "For some people there is that element of believing that there is a chance that I might get it, or I might not get it. They are ready to gamble and take chances. They reason it's all in the hands of God: if I get it, fine, if I do not, I would not. So they definitely get infected." (AIDSCAP, Kenya Final Report, http://www.fhi.org/en/aids/aidscap/aidspubs/special/countryprog/Kenya/kenya1-C.html)

27 This is particularly true if levels of availability and acceptability of preventive measures (assuming that reliability is taken for granted) are low. Resistance to condom use in African countries has been widely documented (Bond and Dover 1997, Mason 1997, Nangendo 1998).

${ }^{28}$ In prospect theory models of decision-making under risk, people underweight outcomes that are merely probable in comparison with outcomes that are obtained with certainty, so that risk aversion is likely to increase when choices involve sure gains and risk seeking in choices involving sure losses (Kahneman and Tversky 1979).
} 
illness, and are therefore likely to die soon. This correlation is before the eyes of everybody in South Nyanza and it enforces the "false" belief that the test actually kills, or at least remarkably accelerates death. In addition, there is a considerable fear of dying socially, i.e. not being able to live a normal life if other people know your status for sure. However, although these motivations are valid, what is worth attention is that, if unprompted, none of the people we asked would consider as part of the answer the fact that they have discovered they are HIV/AIDS-free. Much of what we are speculating should be investigated with more appropriate research methods focusing on the construction of the idea of risk in specific social settings, but certainly the evidence does not contradict this possibility.

c) Social network model. Models MMR3, MFR3, MMR4, and MFR4 introduce variables related to social network perception of risk. In the first two, respondent's network effect is captured through the consideration of the joint effect of two variables: the number of network partners thinking that they are at risk of catching $\mathrm{AIDS}^{29}$, and the dummy controlling for having at least one network partner feeling at risk. Alternatively, model 4 introduces two complementary variables which take into account the possibility of influences reducing respondent's risk perception: the number of network partners thinking they are at no risk of catching AIDS, and the dummy controlling for at least one network partner feeling safe. For both men and women alike, in models MMR3 and MFR3 the level of worry is strongly associated with the number of people in the network that the respondent knows are feeling at risk of AIDS contagion. Similarly, results in MMR4 and MFR4 show consistently a negative and significant coefficient for network variables, indicating that the more the opinion of being safe is spread in the respondent's network, the more she would feel at lower risk herself. As shown in figure 3, the presence of just one person in the network feeling at risk has already a significant effect on the individual probability of feeling at higher risk. But also the marginal network partner sharing this opinion contributes to the increasing feeling of being unsafe (percentages at the top refer to the share of personal network feeling at risk in the respondent's personal network).

[FIG 3 ABOUT HERE]

\footnotetext{
${ }^{29}$ Our data did not allow us to check whether the degree of correct and incorrect knowledge depends on the level of correct and incorrect knowledge of the individual's social networks, because such detailed information was not collected for network partners. But this is likely to be the case if our interpretation of network effect on risk perception as a socially constructed entity is correct.
} 
The direction of network effects is similar for men and women alike. However, men appear to be more influenced than women to some extent, since the presence of just one network partner feeling unsafe about AIDS infection significantly increases the individual probability of feeling at higher risk. In addition, gender differences emerge in the changes of coefficient estimations of the individual characteristics for men. In the case of men, the high score in correct knowledge loses its strong significance and the magnitude of the effect is substantially reduced. The percentage of network partners feeling at risk is more important in shaping individual perception of the risk level she is subjected to, irrespective of her being well-informed about HIV spread mechanisms. In model 4 , having done something to protect against infection no longer has a marginal effect on the individual feeling safer. We did not observe significant variations in previous model estimations in the case of women, where external influences on the degree of risk perception add up to perception of behavioural control and individual knowledge. These latter models show how the contribution of individual variables, such as level of knowledge or perceived control on behaviours, can be mis-estimated.

\section{Conclusions}

The aim of this paper was to explore the impact of the social determinants on the degree of HIV risk perception. Following previous research findings, we assumed that risk perception intensity is an important factor in translating the awareness about the consequences of the epidemic, the knowledge of the spread mechanisms and the knowledge of means to protect against it, into actual adoption of preventive behaviour.

First, we showed how the effect of knowledge of AIDS spread mechanisms on risk perception, as well as of the opportunity to protect oneself against infection, is far less important when personal network influence is considered. If this social aspect is ignored, incorrect conclusions will be drawn on the determinants of risk. The results provide clear evidence that conversations with others alter the entity of risk perceived by individuals. The presence of an effect of personal network influence supports the idea that risk perception is as much a product of individual characteristics and behaviour as it is a collective feeling shared with people with whom they are interacting. Results suggest that men are more susceptible to network influence than women. 
Second, in order to check the impact of AIDS knowledge on the degree of risk perception, we distinguished between correct and incorrect knowledge. While a higher level of correct knowledge significantly increases the perceived level of risk, this is not the case for a higher level of incorrect knowledge. If informal networks are the main vehicles for false beliefs to circulate, they most likely interact deeply with local specific realities (presence of mosquitoes, cases of infecting transfusions in the local clinic, etc.) and might have very different and compensating effects as far as individual risk perception is concerned. It was beyond the aim of this paper to analyse what the actual process of opinion formation on own HIV/AIDS risk is, but this could provide the focus for a longitudinal study about social influence on knowledge and opinion formation. The point is to understand whether the influence of individual characteristics stays constant during the process of opinion formation in the network (uncertainty about risk), or whether, on the contrary, the stronger is the pressure towards opinion uniformity in the network, the weaker are the direct effects of members' individual characteristics ${ }^{30}$.

It is questionable whether the hypothesised direction of the causal relationship between individual risk perception and the amount of knowledge she possesses is effectively a one-way relationship. It could well be that, once people feel threatened by a new disease, this turns out to be an incentive to collect additional information. During a recent return of TB cases in the United Kingdom, it was observed that correct knowledge on how to prevent and cure TB is rare, even among family doctors. Not feeling at any risk anymore, since the disease has been almost eradicated, has led to it being ignored. It is probable that after having registered a $30 \%$ increase of cases in a 6-year span, awareness and risk perception would also work as a motivation to look for information [Davies 1996] ${ }^{31}$.

With an eye to intervention programs and policies, the results suggest the opportunity of using social effects to influence the speed of behavioural change. In order to exploit the potentiality of personal networks, it seems important for information campaigns, particularly those focusing on men, to diffuse information by relying on small informal groups consisting of members that come from the same

\footnotetext{
${ }^{30}$ In a social experiment with small and homogeneous groups of peers, the measure of the mean of peers' opinion, interpreted as an indicator of the magnitude of pressures towards uniformity in the group, is the best approximation to what the individual final opinion is [Friedkin and Cook 1990].

${ }^{31} \mathrm{~A}$ more recent example is probably the search for information on how to prevent anthrax infection, after the bacteria was used as a powerful weapon against people in October 2001.
} 
background and trust each other, rather than generally addressing individuals. Holding regular informal group meetings would also reduce the probability that additional false beliefs are transmitted and therefore modify the information given. Social effects might enhance or rather contrast program efforts aimed at behavioural changes. 


\section{References}

AIDSCAP (1997). Kenya final report, [available on line at: http://www.fhi.org/en/aids/aidscap/aidspubs/special/countryprog/Kenya/kenya1C.html]

AINSWORTH, M. and W. TEOKUL (2000). Breaking the silence: setting realistic priorities for AIDS control in less-developed countries , The Lancet, 356:55-60.

BAUNI, E. and B. JARABI OBONYO (2000). Family planning and sexual behaviour in the era of HIV/AIDS, Studies in Family Planning , 31 (1):69-81.

BEN-ZUR, A., S. BREZNITZ, N. WARDI, and Y. BERZON (2000). Denial of HIV/AIDS and preventive behaviour among Israeli adolescents, Journal of Adolescents, 23:157-174.

BOND, V. and P. DOVER (1997). Men, women and the trouble with condoms: problems associated with condom use by migrant workers in rural Zambia, Health Transition Review, 7 (supplement):377-391.

BUEHLER, C. and H. Kohler (2002). "Talking about AIDS: The influence of communication networks on individual risk perceptions of HIV/AIDS infection and favored protective behaviors in South Nyanza District, Kenya." MPIDR working paper 2002-020.

CALDWELL, J. (1997). The impact of the African AIDS epidemic, Health Transition Review, 7 (supplement 2):169-188.

CAMPBELL, C. (2000). Selling sex in the time of AIDS: the psycho-social context of condom use by sex workers on a Southern African mine, Social Science and Medicine, 50:479-494.

ERICKSON, B. (1988). The Relational Basis of Attitudes, in WELLMAN, B. and S. D. BERKOWITZ (ed. by). Social structure: a social network approach, Cambridge: Cambridge University Press.

ETZIONI, A. (1992). Normative-affective factors: towards a new decision-making model, in ZEY, M. (ed. by). Decision-making. Alternatives to rational choice models, London: Sage.

FONTANET, A. and P. PIOT (1994). State of our knowledge: the epidemiology of HIV/AIDS, Health Transition Review, 4 (supplement):11-23.

FRIEDKIN, N. and K. COOK (1990). Peer group influence, Sociological Methods and Research (19) :122-143.

GREENE, W. H. (2000[1993]). Econometric analysis, Upper Saddle River: Prentice-Hall.

HAMMER, M. (1984). Explorations into meaning of social network interview data, Social Networks, 6:341-371.

INGSTAD, B. (1990). The cultural construction of AIDS and its consequences for prevention in Botswana, Medical Anthropology Quarterly:28-40.

KAHNEMAN, D. and A. TVERSKY (1979). Prospect Theory: an analysis of decision making under risk, Econometrica, 47 (2):265-291.

WATKINS and coll. KDICP, see http://www.pop.upenn.edu/networks

KREMER, M. (1996). Integrating behavioural choice into epidemiological models of AIDS, The Quarterly Journal of Economics (May):549-573.

LAIBSON, D. (1998). Life-cycle consumption and hyperbolic discount functions, European Economic Review, 42:861-871.

LEBLANC, A. (1993). Examining HIV-related knowledge among adults in the US, 
Journal of Health and Social Behaviour, 34 (March):23-36.

LOEWENSTEIN, G. (1996). Out of control: visceral influences on behaviour, Organizational Behavior and Human Decision Processes, 65 (3):272-292.

LONDON, A. S. and R. AROYDS (2000). The co-occurrence of correct and incorrect HIV transmission knowledge and perceived risk for HIV among women of childbearing age in El Salvador, Social Science and Medicine, 51:1267-1278.

LOPES, L. (1987). Between hope and fear: the psychology of risk, Advances in experimental social psychology, 20:255-294.

MASON, O. K. (1994). HIV transmission and the balance of power between women and men: a global view, Health Transition Review, 4 (supplement):217-240.

MATICKA-TYNDALE, E. (1992). Social Construction of HIV Transmission and Prevention Among Heterosexual Young Adults, Social Problems, 39 (3):238-251.

MATICKA-TYNDALE, E., M. HASWELL-ELKINS, T. KUYYAKANOND, M. KIEWYING, and D. ELKINS (1994). A research-based HIV intervention in Northeast Thailand, Health Transition Review, 4 (supplement):349-367.

NANGENDO, S. M. (1998). The perception about condom use and the transmission of the aids pandemic in Kenya, Bulletin of the International Committee on Urgent Anthropological and Ethnological Research, 39:123-140.

NATIONAL COUNCIL FOR POPULATION AND DEVELOPMENT, CENTRAL BUREAU OF STATISTICS, and MACRO INTERNATIONAL (1994). Kenya Demographic and Health Survey 1993, Calverton, Maryland.

NELKIN, D. (1989). Communicating Technological Risk, Annual Review of Public Health, 10:95-113.

NZYUKO, S., R. MORGAN, and D. NYAMWAYA (1991). AIDS and condoms: some notes on the invisible disease, African Urban Quarterly, 6 (1-2):59-73.

OBBO, C. (1991). The language of AIDS in rural and urban Uganda, African Urban Quarterly, 6 (1-2):83-92.

ORUBULOYE, I. O. (1999). Death is pre-ordained, it will come when it is due: attitudes of men to death in the presence of AIDS in Nigeria, in CALDWELL, J., P. CALDWELL, J. ANARFI, K. AWUSABO-ASARE, J. NTOZI, ORUBULOYE I.O., J. MARK, W. COSFORD, R. COLOMBO, and E. HOLLINGS (ed. by). Resistance to behavioural change to reduce HIV/AIDS infection in predominantly heterosexual epidemics in third world countries, Canberra: Health Transition Centre.

ORUBULOYE, I. O., P. CALDWELL, and J. CALDWELL (1993). The role of high risk occupations in the spread of aids: truck drivers and itinerant market women in Nigeria, International Family Planning Perspectives, 19:43-48.

PERUGA, A. and D. CELENTANO (1993). Correlates of AIDS knowledge in samples of the general population, Social Science and Medicine, 36 (4):509-524.

RENNE, E. (1997). Local Institutional interpretations of IUDS in southwestern Nigeria, Social Science and Medicine , 44 (8) 1141-1148.

REYNOLDS-WHYTE, S. (1998). Questioning misfortune, Cambridge: Cambridge University Press.

SCHOEPF, G. B. (1991). Représentations du SIDA et pratiques populaires a Kinshasa, Anthropologie et Societés, 15 (2-3):149-166.

SCHOPPER, D., S. DOUSSANTOUSSE, and J. ORAV (1993). Sexual behaviors Relevant to HIV Transmission in a rural african population. how much can a KAP survey tell us?, Social Science and Medicine, 37 (3):401-412.

SCHRODER, K., S. HOBFOLL, and A. JACKSON (2001). Proximal and 
distal predictors of AIDS Risk Behaviours among inner-city African-American women , Journal of Health Psychology, 6 (2)

SHIINO, W. (1997). Death and rituals among the Luo in South Nyanza, African Study Monograph, 18 (3-4):213-228.

SPEIZER, I. S. and A. YATES (1998). Polygyny and African Couple Research, Population Research and Policy Review, 17:551.

SPEIZER, I. S. (1999). Are husbands a barrier to women's family planning use? the case of Morocco, Social Biology, 46 (1-2):1-16.

UNAIDS/PENNSTATE (1999). Communication Frameworks for HIV/AIDS. A new direction, Geneva: UNAIDS.

VANLANDINGHAM, M., S. SUPRASERT, N. GRANDJEAN, and W. SITTITRAI (1997). Dimensions of AIDS knowledge and risky sexual practices: a study of Northern Thai Males, Archives of Sexual Behavior, 26 (3):269-293.

WATKINS C., S. (2000). Local and foreign models of reproduction in Nyanza Province, Kenya, Population and Development Review, 26 (4):643-689.

WATKINS, S. and E. SCHATZ (2001). Avoiding HIV/AIDS: global advice and local strategies in Nyanza Province, presented at the annual meeting of the Population Association of America, Washington 2001

WEINREB, A. (1999). Estimating HIV+ incidence mortality rates: a method and agenda, presented at the Third African Population Conference, Durban, South Africa.

WOLFF, B. and A. K. BLANC (2000). The role of HIV risk perception on sexual negotiation and condom use among stable unions in high and low risk settings in Uganda, [Forthcoming in African Journal of Reproductive Health]. 
Figure 1

Degree of perceived risk of HIV/AIDS infection, South Nyanza, KDIC II, 1997.
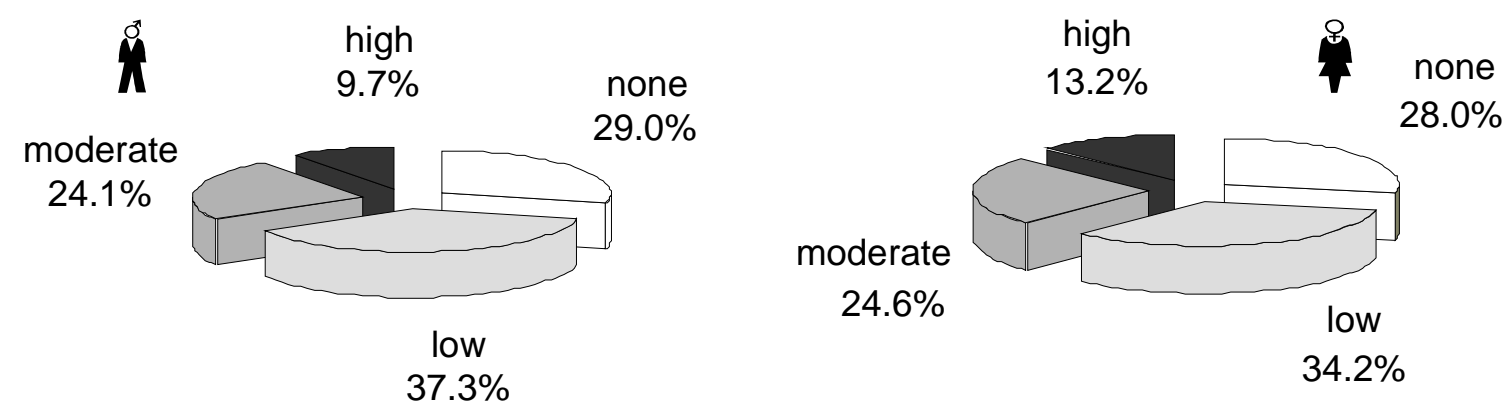
Figure 2

Documented and undocumented modes of HIV/AIDS transmission reported by respondents [percentages by sex], South Nyanza, KDIC II, 1996/1997.
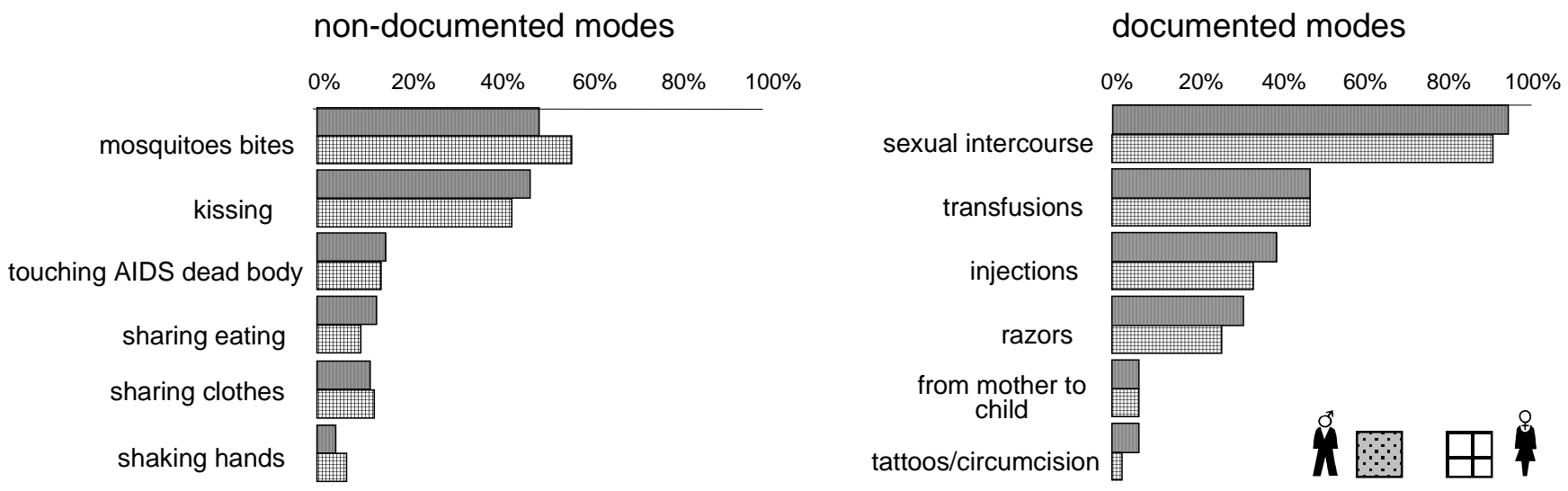
Figure 3

Degree of HIV/AIDS risk perception by sex and proportion of social network feeling at risk (predicted probabilities obtained from ordered logit regressions of risk perception on individual and network characteristics). 1996/1997, South Nyanza,

KDIC II.

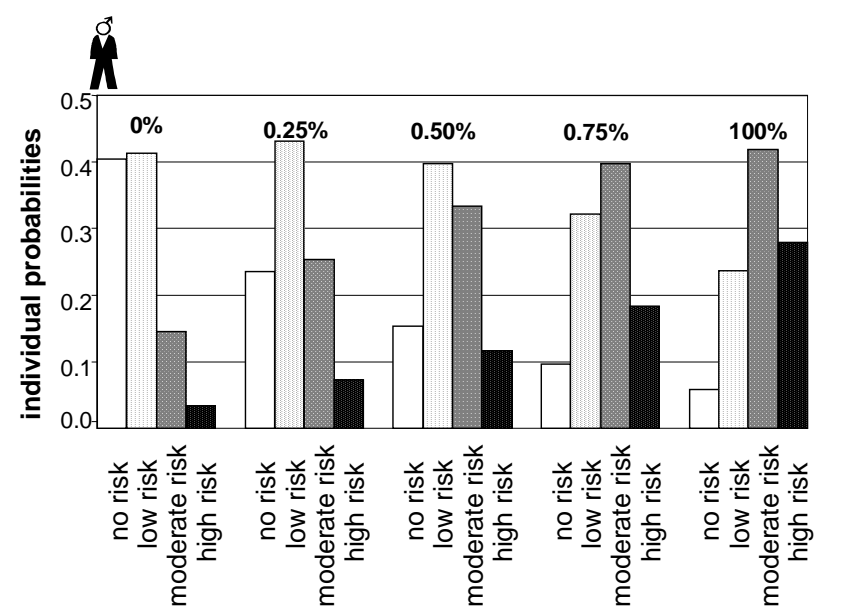

degree of risk perception

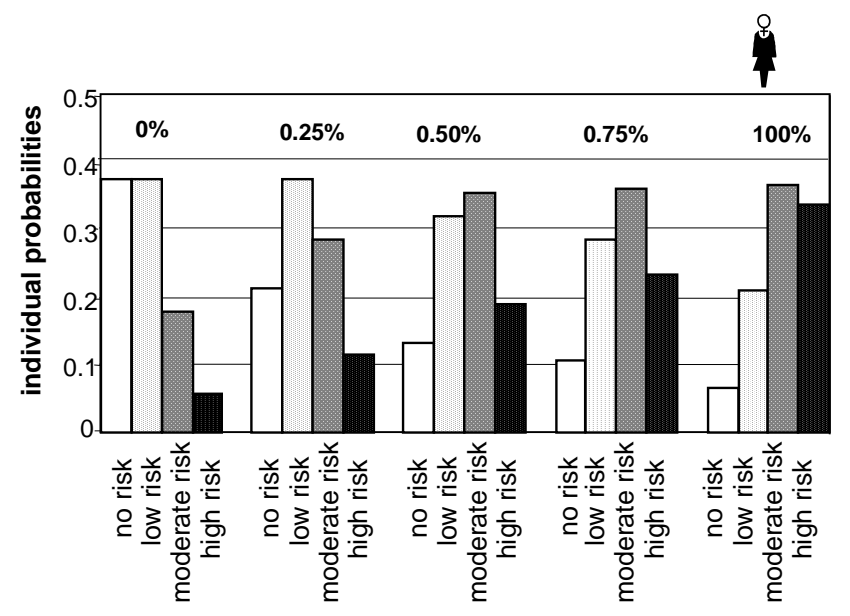

degree of risk perception 
Table 1. Summary of couples' sub-sample characteristics, South Nyanza, KDIC II, 1996/1997.

\begin{tabular}{|c|c|c|c|c|}
\hline \multirow[b]{2}{*}{$\boldsymbol{N}$} & \multicolumn{2}{|c|}{ men } & \multicolumn{2}{|c|}{ women } \\
\hline & \multirow{2}{*}{$\begin{array}{c}424 \\
\text { mean }\end{array}$} & \multirow[b]{2}{*}{ st. dev. } & \multirow{2}{*}{424} & \multirow[b]{2}{*}{ st. dev. } \\
\hline Socio-demo Characteristics & & & & \\
\hline Age & 43.60 & 12.73 & 32.30 & 8.47 \\
\hline Economic index & 8.09 & 5.28 & 8.01 & 5.80 \\
\hline Prop. no education & 8.25 & & 8.01 & \\
\hline Prop. primary education & 60.78 & & 66.04 & \\
\hline Prop.at least secondary education & 31.37 & & 12.50 & \\
\hline Obisa & 24.53 & & 24.53 & \\
\hline Owich & 20.50 & & 20.50 & \\
\hline Kawaghone & 31.37 & & 31.37 & \\
\hline Wakula South & 24.06 & & 24.06 & \\
\hline Polygamous household & 29.90 & & 29.90 & \\
\hline Prop. having lived out S. Nyanza> 6 months & 66.75 & & 37.74 & \\
\hline \multicolumn{5}{|l|}{ AIDS knowledge } \\
\hline Correct knowledge index (mean) & 2.27 & 1.34 & 2.09 & 1.17 \\
\hline Incorrect knowledge index (mean) & 1.41 & 1.45 & 1.43 & 1.47 \\
\hline \multicolumn{5}{|l|}{ Behavioural Variables } \\
\hline Prop. ever used FP & 29.70 & & 31.10 & \\
\hline Prop. having done something to protect from AIDS & 46.70 & & 27.90 & \\
\hline Prop. feeling confortable in suggesting condom & 25.53 & & 27.25 & \\
\hline Prop. husband usually stays in the compound & 90.00 & & 91.27 & \\
\hline \multicolumn{5}{|l|}{ AIDS: perceived risk } \\
\hline Prop. perceiving no risk & 29.01 & & 29.01 & \\
\hline Prop. perceiving small risk & 37.26 & & 33.73 & \\
\hline Prop. perceiving moderate risk & 24.06 & & 24.29 & \\
\hline Prop. perceiving great risk & 9.67 & & 12.97 & \\
\hline \multicolumn{5}{|l|}{ Social Network } \\
\hline Number of network partners (censored) & 2.73 & 1.52 & 2.40 & 1.60 \\
\hline Number of network partners perceiving no-small risk & 1.17 & 1.35 & 0.95 & 1.11 \\
\hline Number of network partners perceiving moderate-great risk & 1.11 & 1.38 & 0.89 & 1.23 \\
\hline Prop. with at least 1 network partner no-small risk & 48.82 & & 42.45 & \\
\hline Prop. with at least 1 network partner moderate-high risk & 24.76 & & 25.71 & \\
\hline
\end{tabular}


Table 2 - Ordered logistic regression: degree of perceived risk of HIV/AIDS infection, 1996/1997, South Nyanza, KDIC II, men.

\begin{tabular}{|c|c|c|c|c|c|c|c|c|c|c|c|c|}
\hline \multirow[b]{2}{*}{ Level of perceived risk } & \multicolumn{3}{|l|}{ MMR1 } & \multicolumn{3}{|l|}{ MMR2 } & \multicolumn{3}{|l|}{ MMR3 } & \multicolumn{3}{|l|}{ MMR4 } \\
\hline & Coef. & Std. Err. & $\begin{array}{l}P>1 \\
z \mid\end{array}$ & Coef. & Std. Err. & $\begin{array}{l}P>1 \\
z \mid\end{array}$ & Coef. & Std. Err. & $\begin{array}{l}P>1 \\
z \mid\end{array}$ & Coef. & Std. Err. & $\begin{array}{l}P>1 \\
z \mid\end{array}$ \\
\hline \multicolumn{13}{|l|}{ Individual Characteristics } \\
\hline Age & -0.012 & 0.045 & & -0.026 & 0.046 & & -0.036 & 0.047 & & -0.037 & 0.046 & \\
\hline Age squared $(/ 10)$ & -0.002 & 0.005 & & -0.001 & 0.005 & & 0.000 & 0.005 & & 0.000 & 0.005 & \\
\hline \multicolumn{13}{|l|}{ Prop. no education } \\
\hline Prop. primary education & -0.029 & 0.360 & & -0.040 & 0.364 & & -0.105 & 0.376 & & 0.107 & 0.372 & \\
\hline \multicolumn{13}{|l|}{ Obisa } \\
\hline Owich & 0.119 & 0.277 & & 0.134 & 0.281 & & 0.258 & 0.286 & & 0.180 & 0.284 & \\
\hline Kawaghone & 0.014 & 0.247 & & 0.028 & 0.249 & & 0.006 & 0.255 & & -0.003 & 0.253 & \\
\hline Wakula South & 0.024 & 0.280 & & 0.042 & 0.286 & & -0.107 & 0.292 & & 0.108 & 0.288 & \\
\hline Polygamous household & 0.388 & 0.223 & * & 0.383 & 0.223 & * & 0.512 & 0.228 & ** & 0.412 & 0.224 & * \\
\hline Economic index & -0.005 & 0.020 & & -0.002 & 0.020 & & -0.011 & 0.021 & & -0.004 & 0.021 & \\
\hline \multirow{2}{*}{$\begin{array}{l}\text { Ever used family planning } \\
\text { lived out of } S \text {. Nyanza }>6 \text { months }\end{array}$} & 0.151 & 0.208 & & 0.109 & 0.216 & & 0.034 & 0.220 & & 0.202 & 0.218 & \\
\hline & 0.192 & 0.203 & & 0.164 & 0.204 & & 0.090 & 0.207 & & 0.153 & 0.207 & \\
\hline \multicolumn{13}{|l|}{ AIDS knowledge } \\
\hline correct knowledge & 0.175 & 0.072 & ** & 0.187 & 0.073 & $* * *$ & 0.091 & 0.074 & & 0.193 & 0.075 & $\star \star * *$ \\
\hline incorrect knowledge & -0.025 & 0.066 & & -0.023 & 0.066 & & -0.047 & 0.067 & & -0.028 & 0.066 & \\
\hline \multicolumn{13}{|l|}{ Behavioural Variables } \\
\hline man usually stays in the compound & & & & -0.119 & 0.323 & & -0.038 & 0.323 & & -0.132 & 0.325 & \\
\hline ever protected fromHIV/AIDS & & & & -0.337 & 0.195 & * & -0.298 & 0.196 & * & -0.171 & 0.198 & \\
\hline \multicolumn{13}{|c|}{ feel confortable in suggesting condom to spouse } \\
\hline & & & & 0.400 & 0.216 & * & 0.313 & 0.221 & * & 0.419 & 0.217 & ** \\
\hline \multicolumn{13}{|l|}{ Social Networks } \\
\hline at least 1 network partner says yes & & & & & & & 0.054 & 0.326 & * & & & \\
\hline number of NWP saying yes & & & & & & & 0.581 & 0.121 & $* * *$ & & & \\
\hline at least 1 network partner says no & & & & & & & & & & -0.628 & 0.229 & $* * *$ \\
\hline number of network partner saying no & & & & & & & & & & -0.258 & 0.075 & $\star \star * \star$ \\
\hline cut point no-low & -1.486 & 1.109 & & -1.946 & 1.181 & & -2.017 & 1.210 & & -2.492 & 1.190 & \\
\hline cut point low-medium & 0.163 & 1.107 & & -0.281 & 1.178 & & -0.137 & 1.206 & & -0.741 & 1.184 & \\
\hline cut point medium -high & 1.760 & 1.112 & & 1.327 & 1.181 & & 1.678 & 1.211 & & 0.934 & 1.187 & \\
\hline LL & -535.713 & & & -532.301 & & & -497.378 & & & -518.129 & & \\
\hline chi-sq. & $27,16(13)$ & & & $31,51(16)$ & & & $101,35(18)$ & & & $59,85(18)$ & & \\
\hline $\mathrm{N}$ & 424 & & & 424 & & & 424 & & & 424 & & \\
\hline
\end{tabular}


Table 3 - Ordered logistic regression: degree of perceived risk of HIV/AIDS infection, 1996/1997, South Nyanza, KDIC II, women

\begin{tabular}{|c|c|c|c|c|c|c|c|c|c|}
\hline \multirow[b]{2}{*}{ Level of perceived risk } & \multicolumn{2}{|c|}{ MFR1 } & \multicolumn{2}{|c|}{ MFR2 } & \multicolumn{2}{|r|}{ MFR3 } & \multicolumn{3}{|c|}{ MFR4 } \\
\hline & Coef. & $\begin{array}{c}\text { Std. Err. } P>\mid z \\
\mid\end{array}$ & Coef. & $\begin{array}{r}\text { Std. Err. } \begin{array}{c}P>1 \\
z\end{array} \mid\end{array}$ & Coef. & $\begin{array}{c}\text { Std. Err. } P>\mid z \\
\mid\end{array}$ & Coef. & $\begin{array}{l}\text { Std. } \\
\text { Err. }\end{array}$ & $\begin{array}{l}P>1 \\
\mathbf{z}\end{array}$ \\
\hline \multicolumn{10}{|l|}{ Individual Characteristics } \\
\hline Age & 0.141 & $0.081 *$ & 0.148 & 0.082 * & 0.129 & 0.082 * & 0.157 & 0.083 & \\
\hline Age squared (/10) & -0.021 & $0.011 *$ & -0.021 & 0.012 * & -0.019 & 0.012 * & -0.023 & 0.012 & ** \\
\hline \multicolumn{10}{|l|}{ Prop. no education } \\
\hline Prop. primary education & 0.578 & $0.258 * *$ & 0.597 & $0.261 * *$ & 0.411 & $0.264 *$ & 0.671 & 0.264 & ** \\
\hline $\begin{array}{l}\text { Prop.at least secondary education } \\
\text { Obisa }\end{array}$ & 0.123 & 0.365 & 0.152 & 0.373 & 0.068 & 0.371 & 0.151 & 0.373 & \\
\hline Owich & -0.162 & 0.278 & -0.019 & 0.286 & 0.093 & 0.287 & -0.058 & 0.290 & \\
\hline Kawaghone & -0.024 & 0.250 & -0.031 & 0.254 & -0.049 & 0.255 & 0.071 & 0.257 & \\
\hline Wakula South & 0.272 & 0.271 & 0.324 & 0.277 & 0.306 & 0.276 & 0.497 & 0.286 & \\
\hline Polygamous household & 0.218 & 0.199 & 0.221 & 0.201 & 0.219 & 0.203 & 0.369 & 0.205 & * \\
\hline Economic index & -0.017 & 0.017 & -0.020 & 0.018 & -0.031 & 0.018 * & -0.022 & 0.018 & \\
\hline Ever used family planning & 0.177 & 0.209 & 0.162 & 0.211 & 0.099 & 0.213 & 0.249 & 0.214 & \\
\hline lived out of $S$. Nyanza $>6$ months & -0.303 & 0.187 * & -0.331 & 0.189 * & -0.24 & 0.191 & -0.363 & 0.191 & ** \\
\hline \multicolumn{10}{|l|}{ AIDS knowledge } \\
\hline correct knowledge & 0.417 & $0.085^{* * *}$ & 0.441 & $0.087^{* * *}$ & 0.341 & $0.089 * * *$ & 0.433 & 0.088 & $* * *$ \\
\hline incorrect knowledge & 0.035 & 0.065 & 0.036 & 0.065 & 0.018 & 0.067 & 0.021 & 0.066 & \\
\hline \multicolumn{10}{|l|}{ Behavioural Variables } \\
\hline man usually stays in the compound & & & -0.478 & 0.336 * & -0.482 & 0.34 * & -0.450 & 0.343 & \\
\hline ever protected fromHIV/AIDS & & & -0.651 & $0.210 * * *$ & -0.66 & $0.213^{* * *}$ & -0.539 & 0.214 & \\
\hline & & & 0.482 & $0.208 * *$ & 0.376 & $0.211 *$ & 0.399 & 0.210 & * \\
\hline \multicolumn{10}{|l|}{ Social Networks } \\
\hline at least 1 network partner says yes & & & & & 0.271 & 0.346 & & & \\
\hline number of NWP saying yes & & & & & 0.348 & $0.139 * * *$ & & & \\
\hline at least 1 network partner says no & & & & & & & -0.962 & 0.235 & $* * *$ \\
\hline number of network partner saying no & & & & & & & -0.124 & 0.080 & \\
\hline cut point no-low & 2.507 & 1.421 & 2.157 & 1.480 & 1.757 & 1.484 & 2.062 & 1.494 & \\
\hline cut point low-medium & 4.032 & 1.430 & 3.727 & 1.489 & 3.413 & 1.492 & 3.713 & 1.502 & \\
\hline cut point medium -high & 5.496 & 1.442 & 5.239 & 1.499 & 5.026 & 1.502 & 5.265 & 1.514 & \\
\hline$\overline{\mathrm{LL}}$ & -544.760 & & -534.899 & & -519.326 & & -522.018 & & \\
\hline chi-sq. & $41,92(13)$ & & $56,67(16)$ & & $87,82(18)$ & & $82,43(18)$ & & \\
\hline $\mathrm{N}$ & 424 & & 424 & & 424 & & 424 & & \\
\hline
\end{tabular}

Significance levels: ${ }^{*} p<0.1 ; ;^{* *} p<0.05 ;{ }^{* \star *} p<0.01 ;$ 